\section{William Higgins and the Imponderable Elements.}

IT is interesting to compare the semi-prophetic speculations of Oersted as so ably stated by Prof. Silvanus Thompson in NATuRE of August 29 with a theory put forward by William Higgins in a book published at Dublin in I814. This work, entitled "Experiments and Observations on the Atomic Theory and Electrical Phenomena," was primarily intended to prove that Dalton's theory had been anticipated by the author in $1789,{ }^{1}$ but some thirty pages in the early part of the book are devoted to a statement of his views on the "imponderable elements."

The following extracts may serve to give some idea of the nature of his surmises :-

"The ultimate particles of ponderable matter are exceedingly minutc, but those of imponderable elements, such as caloric, electricity, and light, are so beyond calculation. The utmost stretch of the human mind can no more estimate the size of those particles than it can measure space and duration. However, their divisibility is limited" (p. 24).

"Every ultimate particle of a metal is surrounded with a small although dense atmosphere of caloric, together with a small portion of the electric or some other subtile fluid... when two atoms unite, the compound becomes surrounded with one common atmosphere of caloric and rejects a third atom of either of its constituents" (p. I3 et seq.).

"When two ultimate particles unite chemically their individuality is destroyed, and they form one solid atom whose capacity is less than its constituents in a detached or simple state, hence it is that caloric is liberated by chemical union. These atoms however retain a sufficient quantity of caloric to furnish them with atmospheres" (p. 20).

"The ultimate particles of different kinds of matter, whether in a solid or gaseous state, do not retain the same quantity of caloric in their respective atmospheres. This probably is occasioned by their different forces of attraction to it. Those particles which attract caloric with most force are surrounded with more of it, in a less space than those particles that attract it with a smaller force" (p. Ig).

"Solids also contain a prodigious quantity of caloric, as may be shewn by deflagrating together nitre, brimstone, and crude antimony, reduced to powder, and intimately mixed" (p. 25).

"Caloric and the electric fluid are antagonistic elements, whereas light and caloric seem to be kind and almost constant associates. The light of the sun, and that produced by artificial means, are accompanied by caloric" (p. 40).

Good conductors are those part of the caloric of which is capable of being readily replaced by the electric fluid. "Dry oxides are non-conductors, as their calorific atmospheres are small and strongly attached to their atoms" (p. 43).

The electric spark inflames gunpowder or alcohol owing to "caloric which is disengaged from these substances or from the air in contact with them." Wires are fused by a battery because of "a rapid dislodgement of the specific heat of the metals by the electric matter," and since a wire remains heated during the passage of a current the electric fluid "must also possess the power of urging on, during its passage, through the battery and conductors, a sufficiency of caloric to supply the waste occasioned by the ignition" (p. 26 et seq.).

In similar fashion he "explains" the luminosity of meteors, why the electric spark causes combustion between oxygen and hydrogen, and

1 See Meldrum, Chem. News, x9ro, for a discussion of his claims on this point.

No. 2239, vOL. 90] why earthquakes and volcanic eruptions are accompanied by thunder and lightning. The production of heat in Rumford's experiment he admits presents a difficulty, and suggests that it might be due to the displacement of some of the specific heat by electricity, which, it was well known, could be produced by friction. He precedes this by saying that "Heat evolved by friction, however unaccountable and mysterious it may appear, is not sufficient to invalidate the doctrine of the materiality of caloric, being only a solitary fact opposed to thousands that tend to establish its existence as an elementary substance" (p. 37).

$\mathrm{He}$ concludes this part of his work with a touch of the true Baconian philosophy:-"The theory, or rather the hypothesis, which I have advanced, on electrical phenomena . . . according to my knowledge is quite new." "So fully convinced am I, at present, of the truth of this doctrine that no vague or superficial objections will be able to stagger my creed; at the same time, I am ready to submit to convincing facts and arguments, for truth should be the sole object of every writer on philosophical subjects" (p. 45 et seq.).

It will be seen that his speculations, though crude, and, of course, erroneous in the light of modern theory, are none the less characterised by considerable lucidity in expression and no little ingenuity in application. In this connection we may well remember the words of Liebig: "All our views have been developed from errors." From the flashing embers of fallacy springs the Phøenix of Truth.

London, W.C., September I.

A. U. N.

\section{Glaciation and Striation.}

Prof. Cole (Nature, September 12, p. 37) would scarcely maintain the assumption that the stones seen in Boulder Clay were in the "englacial" distribution of the materials in closer juxtaposition than we find them in the deposit itself. The tendency of the larger stones to gravitate towards the bottom of the moving and shearing ice-mass through liquefaction and regelation is well illustrated in the Harlow "till." But Prof. Cole seems to forget that a "conglomerate with an ice-cement" would give us a glacial gravel or a "schotter" on the melting of the ice, and not a Boulder Clay. The efficiency as a gravingtool of a grain of quartz or of some harder mineral when caught between the contact-surfaces of two fragments of rock undergoing differential movement can scarcely be doubted.

$\Lambda$ s to the pre-Boulder Clay age of the "Ipswich man," the evidence of which I have examined on the spot, the attention of Mr. J. R. Moir (ibid., p. $3^{8)}$ and others may be fairly directed to the new light thrown upon the question by the Thorley section.

With reference to scratches on flints, I venture to ask Sir Ray Lankester whether in plate $\mathrm{I} 7$ of his monograph (Phil. Trans. R.S., Serics B, vol. ccii., pp. $203 \mathrm{ff}$.) he has not overlooked (I) the fact that the striations shown in Fig. I are on the original cortex of the flint-nodule, and therefore not necessarily connected with glaciation, and (2) the probability that the markings shown in Fig. 2 (enlarged in Figs. 3, 4, 5) are the etched-out skeletons of some spongoid fossil, by humus acids acting differentially as a solvent on the various modifications of the silica found often in the same flint-nodule? Of such differential solvent action I have a large collection of examples, in some cases showing corrosion to the extent of the complete obliteration of the lithological character of the flint as such.

Bishop's Stortford, September 17.
A. IRVING. 